\title{
Estimating risk using multi-gene panel testing; do negative results change the risk?
}

Journal of Human Genetics (2017) 62, 339; doi:10.1038/jhg.2016.125; published online 13 October 2016

Recently, Mannan et al. ${ }^{1}$ reported that multi-gene panel testing provided increased sensitivity for detection of pathogenic mutations, which characterize hereditary breast and/or ovarian cancer syndromes.

I think it is important to recognize that while enormous progress has been made in our ability to identify germline mutations responsible for over $90 \%$ of hereditary breast cancer syndromes, patients who test negative (on multi-gene panel testing) should still be considered for the same screening and prophylactic treatments as those with similarly high pretest probabilities who test positive.
The authors conclude that such tests help 'in identifying patients with a high risk of developing cancer'. However, the gold standard for identifying patients at high risk remains the patient's personal and family history; the likelihood of harboring one of the known genetic risk factors is mitigated through negative testing, but with a given personal and family history, the likelihood of the patient carrying alteration(s) not tested for presumably simply increases for the patient who tests negative. ${ }^{2}$

\section{CONFLICT OF INTEREST}

The author declares no conflict of interest.
Steven M Sorscher

Department of Medicine, Wake Forest University School of Medicine,

Winston-Salem, NC, USA

E-mail: ssorsche@wakehealth.edu

1 Mannan, A. U., Singh, J., Lakshmikeshava, R., Thota, N., Singh, S., Sowmya, T. S. et al. Detection of high frequency of mutations in a breast and/or ovarian cancer cohort; implications of embracing a multi-gene panel in molecular diagnosis in India. J. Hum. Genet. 61, 515-522 (2016).

2 Bevers, T. B., Ward, J. H., Arun, B., Colditz, G. A., Cowan, K. H., Daly, M. B. et al. Breast Cancer Risk Reduction, Version 2. NCCN Guidelines (2015). 